\title{
DICHOS Y REFRANES UTILIZADOS POR JÓVENES Y ADULTOS EN EL MERCADO CENTRAL DEL CANTÓN CENTRAL DE LA PROVINCIA DE PUNTARENAS
}

\author{
Sayings and proverbs used for youth and adults in central market \\ of central canton Province of Puntarenas
}

Jonnathan Salas Alvarado*

\section{RESUMEN}

El presente artículo muestra los resultados obtenidos de un estudio realizado en el año 2012 acerca de dichos y refranes conocidos y utilizados por adultos y jóvenes en el mercado central de Puntarenas. El estudio recopila dichos y refranes conocidos y utilizados dentro del mercado central de Puntarenas mediante la aplicación de un instrumento a 46 personas ( 20 hombres y 26 mujeres) con edades comprendidas entre los 15 y más de 60 años. La idea es conocer cuales son los dichos y refranes que gozan de mayor popularidad y uso entre esta población.

Palabras clave: dicho, refrán, mercado, adultos, jóvenes.

\begin{abstract}
The following article shows the results obtained from a study carried out in 2012. This study is about sayings and proverbs known an used by adults and young people at Puntarenas's central market. The study collects sayings and proverbs by means of the application of an instrument to 46 people ( 20 men and 26 women) whose ages go from 15 to more than 60 years old. The objective was to get to know which are the most commonly used and popular sayings and proverbs for this population.

Key Words: saying, proverb, market, adults, young people.
\end{abstract}

Universidad de Costa Rica, Profesor, Escuela de Filología, Lingüística y Literatura. Costa Rica

Correo electrónico: josa325@hotmail.com

Recepción: 8/10/2014. Aceptación: 30/4/2015. 


\section{Antecedentes}

Actualmente, existen pocas fuentes bibliográficas que resguarden el desarrollo y transformación del léxico puntarenense. Sin embargo, se cuenta con diversidad y cantidad apreciable de informantes quienes son usuarios de la lengua y que pertenecen a esta región y son conocedores del dialecto que ahí se habla.

La importancia de esta descripción yace en el hecho de que el conocimiento acerca de las palabras, dichos, refranes y demás, que caracterizan a la población puntarenense, es evidente, es decir, está siendo utilizado por muchas personas. No obstante, parece una realidad ajena para ciertos grupos de hablantes en la actualidad, quienes no han podido tener contacto directo con estas estructuras, lo cual ha provocado que las mismas caigan en desuso, y sean fácilmente olvidadas, ignoradas y reemplazadas por parte de las nuevas generaciones de hablantes de la Región de Puntarenas, perdiendo de esta manera una invaluable parte de la identidad cultural porteña.

La comunidad Puntarenense en general posee una riqueza lingüística que es, hasta cierto punto, muy diferente a la que se puede encontrar en muchas otras comunidades del país. Esto probablemente debido a su ubicación geográfica y a la función de puerto que ha cumplido desde hace muchos años. A pesar de que muchos comprenden este hecho, es muy poco o ninguno el interés que se le ha dado a la particular forma de hablar del "porteño" a sus dichos y refranes. Esta es la razón fundamental que motiva esta investigación: encontrar esos rasgos particulares para poder recopilarlos y darlos a conocer a la comunidad en general con la idea de que sean accesibles a las generaciones venideras.

Históricamente, Puntarenas ha tenido un papel relevante para el país en general. Sin embargo, parece ser que en el tiempo de la conquista la lengüeta de arena aún no existía. Esto según historiadores como Oviedo. En ese entonces, el puerto que tenía una gran importancia era el de Caldera. De hecho, tal y como lo indica la historiadora Claudia Quirós (1976), hasta al finales del siglo XVIII los puertos de Caldera y la Barranca fueron el escenario de la mayoría de las actividades de importación y exportación de la provincia de Costa Rica.

El puerto de Puntarenas fue habilitado como tal el 29 de abril de 1814, en ese entonces, este fue declarado Puerto Principal de Altura y estaba bajo la jurisdicción político-administrativa de Esparza. Según Valverde (2008), al haberse habilitado como puerto, Puntarenas presenta un gran crecimiento tanto económico como poblacional que hacen que en 1848 se declarara cantón y asumiera el liderazgo en la región.

En cuanto a lo que se refiere al origen y composición de la población de Puntarenas, Valverde (2008) señala que en sus orígenes, esta fue muy heterogénea ya que estaba formada por representantes de diversos grupos que venían de varios orígenes geográficos, tanto nacionales como internacionales. De hecho, la población de Puntarenas crece a gran escala entre los años 1858 y 1930, esto debido mayormente a la migración.

Entre los grupos de mayor numero que llegaron a Puntarenas se puede mencionar el caso de los nicaragüenses quienes ya de por si mantenían una muy buena relación comercial con Puntarenas. Por otra parte, la historia nos muestra a los chinos como otro de los grupos de inmigrantes más destacados dentro de la comunidad puntarenense. La mayor afluencia de chinos, según Valverde (2008) se da en las primeras décadas del siglo $\mathrm{XX}$, la razón principal por la cual toma lugar este fenómeno es la difícil situación política que los chinos enfrentaban es su país en ese momento.

El resultado de la llegada de estos y otros grupos poblacionales a Puntarenas se ha manifestado directamente en su cultura y su idiosincrasia. Naturalmente, el habla de los habitantes de Puntarenas también ha de sufrir una serie de modificaciones que la hacen tan distinta a otros dialectos presentes en el país.

\section{Sobre los dichos y refranes}

Según el diccionario de la Real Academia de la Lengua Española en su vigésima segunda 
edición un dicho va a ser entendido como una palabra o conjunto de palabras con que se expresa oralmente un concepto, también puede entenderse como una ocurrencia chistosa y oportuna. De manera coloquial, podría entenderse como una expresión insultante o desvergonzada. En tanto que un refrán, tal y como lo define la Real Academia de la Lengua Española, es un dicho agudo y sentencioso de uso común.

Por otro lado, el Instituto de Cultura y Lengua Costarricense en su blog considera que los refranes representan "la sabiduría popular, la sabiduría popular donde la filosofía de la vida precisa una amonestación seria o burlona", a la vez consideran que un dicho es "una o varias palabras que expresan un concepto cabal" pudiendo se este una "ocurrencia oportuna o chistosa."

El sitio web, guiascostarrica.com, cita a Cervantes quien en su obra maestra "Don Quijote de la Mancha" ofrece una acertada definición del término refrán, entendiendo a este como "sentencias breves, sacadas de la experiencia y especulación de nuestros antiguos sabios". De acuerdo con esta página, los refranes se han conocido como dichos en algunos países latinoamericanos. Estos, pueden considerar sentencias habituales de carácter anónimo. Sin embargo, y según el sito consultado, muchas de las expresiones literarias de varias culturas han pasado a formar parte del repertorio lingüístico popular de muchas naciones en forma de refrán. Los refranes, son parte esencial del bagaje cultural y lingüístico de un pueblo, especialmente en tiempos en que la tradición oral era la encargada de transmitir la sabiduría popular de generación en generación. Los refranes, según guiascostarrica.com, encierran la sabiduría del pueblo, fruto directo de la experiencia.

Lo que sucede con los dichos y refranes es que son parte del pueblo, son constituyentes de la cultura y la idiosincrasia de un país o región, de tal forma son parte fundamental de la cotidianidad de los individuos que hacen uso de una lengua. Esto ha propiciado el interés de muchos autores en investigar y salvaguardar lo que para muchos es un patrimonio cultural. Es debido a esto que se han realizado innumerables investigaciones de carácter lingüístico y cultural para conocer y trasmitir esta sabiduría popular a las generaciones venideras.

Muchos han sido los estudios vinculados a este campo de la socio-lingüística a nivel nacional e internacional, por ejemplo, en el año 2010, la mexicana Sofía Kamenetskai en su estudio "del dicho al hecho...sobre el conocimiento del refrán en la ciudad de México" se interesa en la producción, la percepción y la actitud que tienen los habitantes de esa ciudad acerca de los refranes. Ella, a través de una encuesta, determina que los refranes están vivos y para la gente de esta ciudad los mismos no han perdido su valor ni su sabiduría y a la vez Kamenetskai logra determinar que los participantes de su trabajo son consientes de que el uso de los refranes es algo que no está ligado a cultura, región geográfica o clase social, estos, de acuerdo a la autora, son propios de los grupos sociales en su totalidad y su uso y frecuencia se mantiene constante en la totalidad de la población.

Por otra parte, Francisco Zuluaga Gómez del departamento de Lingüística y literatura de la Universidad de Antioquia, Colombia. En su articulo "Locuciones, dichos y refranes sobre el lenguaje: unidades fraseológicas fijas e interacción verbal" hace un estudio en el cual pretende determinar las funciones típicas que desempeñan los refranes y dicho o expresiones fijas o unidades fraseológicas en la práctica discursiva y la interacción de los hablantes. El análisis realizado se basa en la teoría del principio de cooperación de Grice, la teoría de la cortesía propuesta por Brown y Levinson así como en el modelo de la teoría de los actos de habla propuesto por Searle. El corpus utilizado por el autor se extrae de artículos de la prensa local y nacional así como de diálogos provenientes de diferentes novelas. El autor hace un análisis de la función semántica y pragmática de los dichos y refranes en los contextos anteriormente descritos.

A nivel más local, en Costa Rica se han elaborado una gran cantidad de libros y recopilaciones de dichos y refranes mejor 
conocidos como costarriqueñismos. Entre ellos se pueden mencionar el diccionario de costarriqueñismos de Carlos Gagini Chavarría de 1919 mismo que ha sido editado en varias ocasiones a lo largo de los años. También, del mismo Gagini se puede destacar el diccionario de barbarismos y provincialismos de Costa Rica que fue publicado por primera vez en 1892. En esta dirección, también se pueden citar los trabajos de Arturo Agüero Chaves en 1996 con su libro El Español de Costa Rica y el Nuevo diccionario de costarriqueñismos de Miguel Ángel Quesada Pacheco que fue publicado en su tercera edición en el año 2001. De la misma forma en el 2002 se publica la primera edición del libro Mil y tantos tiquismos: costarricensismos por parte de Luis Ferreto Acosta. Mas recientemente se puede citar el trabajo de Alf A. Giebler Simonet quien en el 2012 publica la quinta edición de "A lo tico: costarriqueñismos y otras vainas". Todos estos libros y diccionarios lo que buscan es rescatar y promover esos dichos y frases que hacen del español de Costa Rica único dentro de los países hispanohablantes. Se busca con ellos conservar esa "sabiduría popular" para el disfrute de las nuevas generaciones. En el caso de Giebler, este autor se preocupa no solo de hacer una recopilación muy completa de costarriqueñismos sino que también brinda información socio-cultural e histórica acerca del uso y origen de ciertos términos. De la misma forma, provee una pincelada de lo que él considera forma parte innegable de la cultura e idiosincrasia tica.

Así mismo, se han realizado diversos estudios en relación con el tema de los dichos y refranes en diversos contextos de la sociedad costarricense. Por ejemplo, se puede mencionar el trabajo realizado por Marjorie Jiménez Castro con respecto al diccionario de costarriqueñismos de Arturo Agüero. Dentro de su investigación "Índices de mortandad léxica en frases zoonímicas", Jiménez busca encontrar cuales de estas frases se han dejado de usar o están en proceso de desuso por parte de los hablantes de español del área metropolitana para poder determinar el porcentaje de mortalidad léxica así como las posibles causas que han podido contribuir a las eventual desaparición de dichas frases.

Por otra parte, Gabriela Ríos González publica un artículo en el año 2011 acerca de los costarriqueñismos en el DRAE, en su investigación, Ríos toma un grupo de costarriqueñismos publicados en el vigésimo segunda edición del Diccionario de la Real Academia de la Lengua Española y encuesta a un grupo de personas de diversas edades para así determinar cual es el uso de cada uno de los términos seleccionados describiendo así que muchos de ellos son desconocidos por las nuevas generaciones de la misma forma que existen otros que a pesar de no aparecer registrados en ningún diccionario de costarriqueñismos son contemplados dentro del DRAE como tales.

Continuando sobre esta misma línea de acción, Sergio Cordero Monge presenta en el 2007 su estudio sobre la marcación lexicográfica en el diccionario de costarriqueñismos de Arturo Agüero Chaves. Lo que el estudio busca es comentar la forma en que las marcas lexicográficas se presentan en el diccionario previamente mencionado.

Por su parte, Giselle Chang Vargas en el año 2005 publica un artículo con base en un estudio realizado acerca de los costarriqueñismos en el léxico del boyeo. Dentro de este estudio Chang lo que busca es complementar otros estudios en relación al léxico o vocabulario utilizado en el boyeo costarricense. La misma Chang en conjunto con Ximea del Río Urrutia realiza un estudio llamado "En el Golfo de Nicoya, Una aproximación etnográficosemántica en Chomes, Costa de Pájaro, Isla Chira y Puntarenas Centro". En este estudio las autoras se interesan en el estudio del léxico y jerga relacionada a la pesca en las áreas anteriormente mencionadas.

De tal forma, se puede apreciar que ha habido una gran cantidad de investigadores interesados en rescatar y difundir aspectos referentes al español de Costa Rica y sus variantes. Sin embargo, ha sido muy poco el trabajo que se ha realizado directamente en el cantón de Puntarenas, mismo que debido a sus 
características de Puerto posee una diversidad lingüística única en el país. Muchas han sido las influencias que han tenido los habitantes de Puntarenas a lo largo de los años que han motivado cambios en sus hábitos y costumbres. El lenguaje, como fenómeno social que es tampoco ha escapado a las influencias razón por la cual es válido e interesante estudiarlo con el objetivo de preservar aspectos propios del mismo.

\section{Aspectos a considerar}

\subsection{Léxico}

Según el diccionario de la Real Academia de la Lengua Española, en su vigésima edición, se entiende al léxico como "el vocabulario, conjunto de palabras de un idioma, o de las que pertenecen al uso de una región, una actividad determinada, a un campo semántico dado, etc". Con base en esta definición, es posible establecer que el léxico entonces es un elemento perteneciente a un grupo de personas que a su vez compartido por los miembros de este grupo creando con esto sentido de pertenencia e identidad. Bajo esta misma línea de pensamiento Chang (2009, p 107) establece que "el léxico es un referente indentitario, pues aunque los miembros de una sociedad utilicen la misma lengua, es obvia la existencia de particularidades comunicativas entre los hablantes de diferentes grupos sociales y regionales" por tanto es posible entender que El léxico identifica a una comunidad y o grupo y es esta misma comunidad la que es capaz de mantenerlo y transmitirlo a través del tiempo, de una generación a otra.

Por otra parte, pensar que el léxico de una región o grupo social va a permanecer invariable con el paso del tiempo es en cierta forma ilógico debido a que las lenguas al ser elementos sociales no pueden permanecer estáticas e inmutables. Y es que una lengua viva está en constante cambio debido a la interacción entre sus hablantes y la influencia de agentes externos, tal y como lo presenta Jiménez (2012, p125) "Los crecientes procesos de industrialización y globalización han venido afectando todos los ámbitos de nuestra existencia: la convivencia, los espacios, las fuentes de trabajo, las prioridades, la cultura $y$, por supuesto, el lenguaje" sin embargo esta misma autora considera que aun a pesar de estos constantes cambios producidos por medios tecnológicos como la televisión y el internet existen poblaciones y o grupos que conservan información muy valiosa en relación a la historia local misma que se manifiesta en forma de frases y palabras muy propias.

El léxico cambia, es un hecho, sobre este punto, Castillo (2002) señala que existen dos tipos de factores que afectan o inciden, de manera positiva o negativa en los contactos que existen entre lenguas. Estos factores pueden ser externos o internos. La autora explica que son factores internos aquellos que poseen un carácter estructural o lingüístico por ejemplo, si una estructura presenta puntos débiles es posible que otros elementos o estructuras se posicionen dentro de las estructuras ya existentes o las sustituyan. Los factores externos, por otra parte, van a considerar aspectos psicológicos y sociales, ente estos destacan actitudes de rechazo hacia los cambios o palabras.

En lo que respecta al léxico, es importante considerar la existencia de dichos y refranes ya que los mismos son elementos lingüísticos muy propios de los grupos sociales. Los dichos tanto como los refranes se ubican dentro del léxico de los habitantes de una región especifica y son, igual que cualquier otra expresión, transmitidos de una generación a otra. Sin embargo, se ha dicho o más bien se ha tenido la creencia de que estos están cayendo en el desuso o que simplemente son "propiedad" o forman parte del habla de ciertos grupos que poseen características muy particulares. Sobre este punto, la autora mexicana Sofía Kamenetskaia se refiere a la creencia que existe acerca de la disminución en lo referente al uso de frases o palabras que identifican a un grupo en particular. Muy específicamente la autora se refiere a refranes, mismos que son componente fundamental del léxico de varios grupos. Ella establece que existe la creencia u opinión de que los refranes son más propios de las zonas rurales 
más no de las zonas urbanas y que además, en el caso de las zonas urbanas, quienes hacen uso de los mismos son las personas de bajo nivel educativo. Es también parte de esta creencia el pensar que son únicamente las personas adultas quienes conocen y hacen uso de estas frases ya que los jóvenes o los desconocen o simplemente no hacen uso de ellos. Sin embargo, gracias a un estudio realizado por ella misma se logra entender que "los refranes no se están perdiendo, que esta tradición transmitida de padres a hijos persiste" (Kamenetskaia, 2010, p.84). Además de esto, Kamenetskia logra demostrar que los refranes no son propios solamente de las zonas rurales y que no solamente la gente con baja escolaridad hace uso de ellos. De hecho, según lo establece ella misma, "las personas en todas las categorías de sexo, edad y escolaridad supieron los refranes por igual, más aún, en algunos casos los jóvenes y la gente culta Presentaron mayor interés hacia los refranes y su legado que las personas mayores y de bajo nivel de estudios" (Kamenetskaia, 2010, p.84).

Es entonces apreciable la estrecha relación que hay entre el léxico, propiamente entre los dichos y refranes, y la cultura o la sociedad en la cual nacieron, viven y se transmiten hacia otras generaciones e incluso hacia otras culturas alrededor del mundo. Son elementos lingüísticos tan trascendentales que en muchos casos sobre pasan las barreras del tiempo y la distancia.

\subsection{Léxico e Identidad Cultural}

La cultura esta intrínsecamente relacionada a muchos aspectos dentro de los grupos sociales, uno de estos, quizás uno de los más evidentes es el uso del lenguaje. Yule (2010) entiende a la cultura como un término que se refiere a todas las ideas y asunciones con respecto a la naturaleza de las cosas y las personas que aprendemos cuando nos convertimos en miembros de grupos sociales. El considera que la cultura puede definirse como "un conocimiento socialmente adquirido" (Yule, 2010 p. 287), este es un conocimiento adquirido, en primera instancia, de manera inconsciente que posteriormente se vuelve consiente. Esto generalmente ocurre posterior al desarrollo del lenguaje. Con las palabras que adquirimos, nuestro conocimiento y por ende nuestra cultura se desarrolla enormemente.

El lenguaje es un elemento vivo que se encuentra en constante cambio. $\mathrm{Y}$ son estos cambios los que eventualmente logran dar origen a los acentos y dialectos. Un acento, según lo entiende Yule (2010) es una distinción apreciable en aspectos de pronunciación y entonación de una lengua que identifican a un hablante de manera social y regional. Por otra parte, un dialecto se entiende como una distinción lingüística en aspectos tales como gramática y vocabulario.

Según Espinoza (2012), existen muchos factores que definen a los dialectos. Las lenguas van adquiriendo características especiales que son dadas por situaciones geográficas, sociales, culturales o estilísticas. Es este conjunto de variantes las que "enriquecen las hablas regionales y les dan connotaciones especiales, e igualmente permiten el surgimiento de los llamados dialectos" (Espinoza 2012, p5)

Un dialecto es propio de una región o grupo en particular. Este está estrictamente relacionado con la cultura. Es en este punto donde es pertinente el hacer referencia a la cultura nuevamente. Según Robles (2002), existe una distinción entre la llamada cultura con mayúscula y la cultura con minúscula. Se entiende como cultura con mayúscula a la que engloba aspectos tales como la literatura, arte, historia, entre otros. La cultura con minúscula, por otra parte, es la que esta relacionada a aspectos tales como la actuación y la vida cotidiana de un grupo de personas, la idiosincrasia de un país o región que es representada mediantes comportamientos, actitudes, hábitos y costumbres. Ramos, propone otra distinción aún más específica, el concepto de cultura en la lengua y la lengua en la cultura. Segú ella, la cultura en la lengua está relacionada a los aspectos culturales que se reflejan en el uso de ciertos esquemas lingüísticos, formas o estructuras. En este apartado destacan ciertas formas de tratamiento tales como el uso de indicativo y el subjuntivo. En lo referente al concepto de lengua en la cultura, es posible 
mencionar aspectos que tienen relación más directa con lo que son las estructuras lingüísticas y muy en especial al léxico que se vincula a determinadas situaciones y acciones culturales de comunicación. En este apartado destacan las frases hechas, los modismos, los refranes y el vocabulario utilizado en ocasiones especiales o lugares específicos.

De acuerdo con Ramos (2000), "El proceso de construcción de identidad está vinculado al contexto social en el que se desenvuelven los individuos, a su cultura" (p.421). Es aquí en donde, según la autora, existe una red de significados mediante los cuales le expresa la identidad y muchos de estos significados se encuentran dentro de las formar léxicas, en habla. Y esta esta habla la que "nos permite dar cuenta y darnos cuenta de nuestros grupos de pertenencia, de nuestro ser y estar en el mundo" (Ramos 2000 p.421). Por tanto, la lengua es sin duda alguna, un elemento que define y refuerza la identidad de los grupos sociales y el carácter dinámico del mismo se manifiesta en el uso de ciertos elementos léxicos. $Y$ es que tal y como lo establece Chang (2005) "El patrimonio intangible se compone de múltiples expresiones que identifican la cultura de un pueblo $\mathrm{y}$, entre ellas, el lenguaje ocupa un lugar esencial" (p.77).

De tal forma no es prudente divorciar el lenguaje de la cultura, ambos están relacionados y crecen, se modifican y evolucionan juntos. Sobre este punto, Chang (2009) considera que "el dinamismo y la interrelación entre lengua y cultura es un factor clave en la generación de estas formas diferenciadas, pues las transformaciones de una sociedad en el transcurso de su historia provocan cambios lingüísticos" (p.107).

\subsection{Costarriqueñismos}

Según el diccionario de la Real Academia de la lengua Española, se entiende como costarriqueñismo a aquel vocablo, giro o locución propios de los costarricenses.

Agüero (1996) en su diccionario de costarriqueñismos establece un marco histórico bastante interesante que describe de manera detallada los procesos e influencias extrajeras que llevaron al Español de Costa Rica a ser lo que es hoy. Por ejemplo, dentro de sus consideraciones y notas iniciales Agüero señala los hechos que han afectado al habla popular de este país. Por ejemplo algo interesante que destacar es el hecho que dentro del área centroamericana Costa Rica fue de los últimos territorios en colonizarse. Por ejemplo, según Agüero, en nuestro país se escucha por primera vez el español en 1502 pero es hasta 1561, 59 años después es cuando se inicia el proceso de conquista de manera oficial. Antes de ese momento los conquistadores ya habían estado en lugares como México, Centroamérica y las Antillas por tanto el español que llega al país ya venia influenciado por voces indígenas y demás.

Además de los indigenismos traídos por los colonos, nuestro español cuenta con los indigenismos propios de nuestro país así como de voces provenientes de otras latitudes tales como los galicismos, los anglicismos y las voces provinciales de los españoles que nos conquistaron. Por lo tanto lo que conocemos como español de Costa Rica ha sido un proceso lingüístico constante que ha tomado mucho tiempo y aun está en evolución.

Los costarriqueñismos describen a grandes rasgos elementos culturales y muy propios de este país y sus hablantes. Según Giebler (2012), "somos muchos los ticos, que ni sabemos ni nos damos cuenta cuales de las palabras que usamos cotidianamente son costarriqueñismos. Simplemente, porque los aprendimos desde la infancia y estamos acostumbrados a seguirlos usando". (p.16).

$Y$ es que es un hecho, todos los ticos usan los costarriqueñismos. Unos en mayor medida que otros, "se dan muchos casos, donde una persona utiliza un sinnúmero de costarriqueñismos durante una conversación y la otra no" (Giebler 2012. p 19). Es de seguro que el uso de los costarriqueñismos va a depender del contexto, la confianza entre los interlocutores, el nivel educativo o simplemente el estado de ánimo de los hablantes. Los costarriqueñismos son parte del léxico de un grupo y quienes hacen uso de ellos se sienten integrados a determinados grupos sociales. De cierta forma, 
esos dichos y refranes muy propios de este país o más específicamente de regiones o lugares van a generar un sentido de pertenencia a los individuos que cotidianamente hacen uso de ellos. De hecho, una persona foránea, aunque sea solamente de otra parte del país, es fácilmente identificable desde el momento mismo en que abre la boca y hace uso de su léxico particular.

Giebler considera que el habla del costarricense varía mucho, según él, hay situaciones y contextos muy específicos que llevan a los "ticos" a hacer uso de ciertas palabras o no. Por ejemplo, cuando se trata de grupos heterogéneos o en el caso de grupos de personas que tienen cierto nivel de confianza entre ellos (amigos del barrio, compañeros de colegio o de trabajo), personas de la misma edad o personas provenientes de diferentes países de habla hispana.

Considerando esos aspectos es posible entender que aun a pesar de que una persona haga un uso cotidiano de ciertos dichos o refranes, hay situaciones muy particulares que las hacen limitar su léxico o simplemente realizar un cambio en su registro de habla. Estos fenómenos lingüísticos son los que eventualmente podrían afectar estudios léxicos como este.

\section{Metodología}

\subsection{Lugar y población}

Esta investigación tiene lugar en el mercado de Puntarenas. Mismo que fue visitado en varias ocasiones para la recolección de datos que posteriormente fueron utilizados en la creación de un instrumento que iba a medir la frecuencia y conocimiento de quienes visitan o trabajan en el mercado acerca de los dichos y refranes. Para la realización de esta investigación se contó con la participación de un total de 19 personas quienes fueron entrevistadas de manera abierta y casual. Se buscaba únicamente que brindaran la mayor cantidad de corpus lingüístico posible. Por ende se buscó motivarlos a hablar de temas cotidianos tales como la vida en el mercado, su infancia, su opinión acerca de la comunidad en que viven, entre otras con el objetivo de que utilizaran dichos y refranes de la manera más natural posible. Estos participantes todos son personas que laboran en los tramos del mercado. Todos y todas son personas originarios de Puntarenas que viven en lugares como el Barrio del Carmen, Chacarita, Fray Casiano, El 20 de noviembre, El Roble y Barranca.

Cuando se logra desarrollar el instrumento a base de las entrevistas, se cuenta con la ayuda de un total de 46 participantes, 20 mujeres y 26 hombres, con edades comprendidas entre los 15 y más de 60 años. Se logra determinar cuales son los dichos más comunes dentro del mercado así como lo utilizados que estos son por parte de los hablantes.

\subsection{Proceso a seguir}

Para la realización de este proyecto de investigación se sigue un proceso que contempla 4 fases muy específicas que se describen a continuación:

\subsubsection{Revisión bibliográfica y estudio de la cuestión}

Esto se logra mediante la revisión de recursos tanto impresos como digitales en los cuales se vislumbre información referente a dichos y refranes, investigaciones realizadas en torno al tema así como fuentes bibliográficas que contengan datos relacionados al cantón de Puntarenas y a su mercado con el objetivo de realizar un reseña histórica con el fin de entender el contexto en el cual se va a estar trabajando. Basado en esto, se logra recopilar información valiosa así como una lista de dichos y refranes costarricenses con el objetivo de ilustrar el tema a tratar.

\subsubsection{Visitas al mercado central de Puntarenas y entrevistas a trabajadores del mercado}

Se realizan un total de 5 visitas al mercado central de Puntarenas en las cuales 
se logra entrevistar a 19 personas, hombres y mujeres de diferentes edades. Durante estas entrevistas el objetivo era conseguir que los participantes hicieran uso de dichos y refranes que ellos utilizan en su vida cotidiana. Se buscan conversaciones naturales con temas que hicieran sentirse cómodos a los hablantes. Entre los temas más recurridos se pueden mencionar: La vida en el mercado, la vida en Puntarenas, la Puntarenas de antaño en contraste con la Puntarenas de ahora, fenómenos naturales de gran relevancia para los Porteños tales como el terremoto del pasado 5 de setiembre del 2012 entre otros.

\subsubsection{Elaboración de un instrumento y su aplicación}

Con base en las entrevistas realizadas a 19 personas dentro del mercado central de Puntarenas se logra elaborar un instrumento en el cual se hace una lista de 55 dichos que fueron utilizados una o más veces por los entrevistados anteriormente descritos en la segunda etapa de la investigación. Se busca preguntar a la gente del mercado si conoce esos dichos o no y si hace uso de los mismos o no. De la misma forma, se les presenta una lista de 20 refranes tomados del blog del el Instituto de Cultura y Lengua Costarricense (2005) esto debido a la ausencia de refranes en las entrevistas realizadas en el mercado. Al igual que con los dichos se les pregunta a los participantes del estudio si conoce o no el refrán y si hace uso del mismo o no. De la misma forma, se consulta a los participantes si conocen otras versiones o variantes de los dichos y refranes que se le presentaron.

Para la aplicación del instrumento nuevamente se hacen varias visitas al mercado y se logra contar con un total de 46 participantes, 20 mujeres y 26 hombres, todos habitantes de la región de Puntarenas, la mayoría nacidos y criados en el cantón central de esta provincia del pacifico. Algunos trabajadores del mercado, otros simplemente personas que por una razón u otra frecuentan el mercado ya sea para realizar compras, almorzar o simplemente pasar el tiempo. Estos 46 participantes son clasificados en 4 grupos por edades: de 15 a 25 años, de 25 a 40 años, de 40 a 60 años y más de 60 años. En su mayoría se cuenta con personas que tienen entre 40 y 60 años aunque también hay buena presencia de personas de edades comprendidas entre los 25 y 40 así como de personas mayores de 60 años. El grupo menos representado es el de personas con edades comprendidas entre los $15 \mathrm{y} \operatorname{los} 25$.

\subsubsection{Análisis del instrumento}

Se realiza un análisis de todos los dichos y refranes presentados a los participantes. Se analizan todos los datos de manera separada tanto por sexo como por edad, esto con el objetivo determinar si las variables de la edad y el sexo influyen o no en el conocimiento y uso de ciertas frases.

Al final, después de hacer un análisis individual se hace un copilado general que considera toda la información recolectada para así determinar que tanto conocen y hacen uso los participantes de los 55 dichos y los 20 refranes que se les presentaron.

Se busca presentar una lista con los dichos y refranes más comunes según los datos arrojados por el instrumento que se aplicó a estas 46 personas. De la misma forma, se espera conocer que otras variantes de esos dichos y refranes conocen los participantes del estudio.

\section{Resultados}

\subsection{Dichos conocidos utilizados por la población del mercado central de Puntarenas}

Según lo demuestran los resultados, los nueve dichos más populares, que dicho sea de paso son conocidos por la totalidad de la población entrevistada se enlistan a continuación: "mamita", "mi amor", "sia tonto", "inombres!”, "ahuevado", "Pura vida”, "vuelto”, "ponerse vivo" y "plata". 
En esta lista se encuentran dichos que ya de por si son ampliamente populares en todo el territorio nacional, tales como "plata", "vuelto" y "Pura vida". Sin embargo, según manifestaron varios de los entrevistados "en el mercado todo lo que se necesita es Mamita y mi amor", al parecer estos "cariñativos" son ampliamente conocidos por la población para diversos fines. Esto tiene sentido ya que si se está hablando de un mercado en el cual se maneja una relación cliente-vendedor, es totalmente comprensible que palabras como estas sean conocidas y utilizadas.

Un dato muy interesante es que la lista de los trece dichos mas utilizados por la población del mercado muestra unos cambios significativos si se le contrasta con la lista anteriormente presentada. Los dichos más usados por las personas del mercado de Puntarenas son: "Vacilar", "mi amor", "Pura vida", "vuelto", "ponerse vivo", "wila", "mamita", "mi chiquita", "borracho", "okey", "nada que ver", "sia tonto" y "plata".

En este caso, únicamente el dicho "vacilar" es el que es utilizado por la totalidad de la población. Dichos como "mi amor" y "pura vida" son usados por $97.8 \%$ de los entrevistados, "Vuelto" y "ponerse vivo" son utilizados por $93.4 \%$ de los colaboradores en tanto que los restantes 8 dichos son usados por 91.3\% de los entrevistados.

Es interesante que a pesar de que la totalidad de la población dice conocer palabras tales como "ahuevado" y "inombres!", estos no aparezcan dentro de los más utilizados.

En relación al género, es posible observar que en lo que respecta a la población femenina en su totalidad dichos como "papi", "wila", "mamita", "mi chiquita", "mi amor", "okey", "nada que ver", "sia tonto", “inombres!", "ahuevado", "pura vida", "vuelto", "Ponerse vivo", "juepuña”, "plata” y "pegar gritos" son conocidas.

Sin embargo, ninguno de los dichos es utilizado por la totalidad de las entrevistadas, los que son más utilizadas, mismos que corresponden a $95 \%$ de la población entrevistada, son dichos como: "wila", "mi amor", "no hay que echar para atrás", "okey", "un día suave", "es matado", "vuelto" y "Pura vida". De tal forma, no todos los dichos que son conocidos por toda la población son usados por los mismos.

Por otra parte, los hombres entrevistados manifiestan, en su totalidad, conocer dichos como: "chinear", "mamita", "pulsear", "sia tonto", "vacilar", "iNombres!”, "ahuevado", "Pura vida", "vuelto", "pelar el ojo", "ponerse vivo", y "plata". Mostrando así ciertas correspondencias con lo manifestado por las entrevistadas.

Visto desde un ángulo en el cual se contrastan los dichos que son conocidos por un género y otro, es posible apreciar que existen varios dichos que son comunes tanto para la totalidad de la población masculina como para la totalidad de la población femenina, tal es el caso de dichos como: "Ponerse vivo", "plata", "mamita", "sia tonto", "ahuevado", "nombres" y "vuelto".

Sin embargo, son únicamente conocidos por toda la población masculina dichos como: "chinear", "pulsear", "vacilar" y "pelar el ojo". En el caso de la población femenina, son conocidos por la totalidad de la población dichos como: "pegar gritos", "nada que ver", "okey", "mi amor", "papi" y "wila".

En lo referente al uso de los dichos dividido por género, se observan los siguientes detalles: No existe ningún dicho que sea utilizado por la totalidad de la población entrevistada, lo más cercano al total es una lista que es utilizada por 95\% de las entrevistadas, en esta lista destacan dichos como: "wila", "mi amor", "no hay que echar para atrás", "un día suave", "es matado", "pura vida" y "vuelto".

En el caso de los hombres entrevistados, la totalidad de la población manifiesta hacer uso de los siguientes dichos: "Pura vida", "vacilar" y "mi amor". De tal forma que los que son comunes en ambos sexos en lo que respecta a la mayoría son: "mi amor" y "Pura vida". "Vacilar", el cual es el dicho más utilizado no es utilizado por la totalidad de las mujeres más si por la mayoría de los hombres entrevistados.

Por otra parte, es importante señalar el otro extremo, los dichos que no gozan de tanta popularidad entre los participantes del estudio, entre ellos destacan: "Mano e' pulpo", "di", 
“vestidura”, “puñalados”, “yay”, “pa'ca”, “veá”, "pellejear", "menear", "perro que bebe huevos", "ni quemándole el hocico", "un día suave" y "quemar un lugar".

El dicho "mano e' pulpo" al igual que "di" son los que gozan de menor popularidad entre los entrevistados, cada uno es conocido únicamente por un $65.2 \%$ de la población.

Algo relevante en la lista anteriormente presentada es que esos 12 dichos son, en su mayoría muy coloquiales, incluso podría pensarse que son utilizados por personas de escasa escolaridad. Esa es quizás la razón por la cual no son tan conocidos entre la totalidad de la población entrevistada, sin embargo o es un dato que se pueda precisar debido a que no se indagó acerca de la escolaridad de la población.

$\mathrm{Si}$ se analizan los datos desde la perspectiva de ambos géneros, los datos se vuelven mucho más interesantes. Por ejemplo, para la población femenina, los 5 dichos menos conocidos son: "Puñalados", "di", "un día suave", "pellejear", "menear".

Absolutamente todos estos aparecen en la lista general de los dichos menos conocidos por la población, un dato interesante es el que tiene relación al conocimiento que posee la población del dicho "di", mismo que es una variante de la palabra "diay". "Di" es muy popular entre la población más joven pero no así entre la población mayor. La mayoría de los entrevistados se ubican en edades superiores a los 40 años, quizás eso explica la poca popularidad de tal dicho.

En lo referente a la lista de los dichos menos populares dentro de la población masculina cabe destacar los siguientes: "Di", "mano e' pulpo", "vestidura", "veá", "yay", "pa'ca” y "pulñalados".

En este caso se logra encontrar como coincidencias entre ambos géneros términos como "di" y "puñalados". Además, absolutamente todos los dichos anteriormente mencionados aparecen dentro de la clasificación general de los dichos menos conocidos por la totalidad de la población. El caso de "di" nuevamente puede ser explicado debido a que la mayoría de los entrevistados fue gente con edades superiores a los 40 años y este es un dicho que le es más común a un estrato más joven la población del mercado. Sobre todo, según varios de los entrevistados es muy común que lo utilicen en mensajes de texto y chats.

En relación al uso de los dichos, los menos usados según la totalidad de la población son los que destacan en la siguiente lista: "mano e' pulpo", "di", "vestidura", "puñalados", "veá", "a manos limpias", "pa'ca", "pellejear", "yay", "toda esa cuestión", "ver y desear".

En el caso de las mujeres, los dichos menos utilizados se enlistan a continuación: "mano e' pulpo", “puñalados", “a manos limpias", "di" y "pa'ca".

El dicho "mano e' pulpo" vuelve a aparecer a la cabeza de los menos utilizados por la población. Un dato interesante es que muchas de las personas afirman haber escuchado o utilizado "tiene más manos que un pulpo".

Para la población masculina en particular, los dichos menos utilizados son los que se destacan a continuación: "mano e' pulpo", "di", "vestidura", "veá" y "puñalados".

En este caso nuevamente "mano e' pulpo" y "di” aparecen de nuevo a la cabeza de los dichos menos utilizados según la población masculina.

Si se analizan los resultados basándose en la variable generacional, los datos que se obtienen son bastante interesantes. Primeramente, es importante clarificar que para los fines de este estudio se va a entender como población joven a los que su edad vaya de los 15 a los 40 años y se entenderá como población adulta a aquella que cuente con una edad que vaya de los 40 a más de 60 años.

Basado en los datos arrojados por el instrumento aplicado, los dichos más conocidos por la población adulta son los siguientes: "Nada que ver", "sia tonto", "vuelto", "carajada", "toda esa cuestión", "horita", "es matado", "jodida", "llaradera", "menear", "lucharla", "quemar un lugar", "ver" y "desear", "pa'ca", "a manos limpias" y "un día suave".

Todos ellos son conocidos por la totalidad de la población adulta, la mayoría de ellos son palabras que por diversas razones ya no son utilizadas, sobre todo están muchas de ellas en desuso por parte de poblaciones más jóvenes, un caso muy claro es "pa'ca", "menear", "carajada" 
y "horita". Muchas de ellas indican falta de educación para algunos hablantes.

En lo que respecta a la población más joven, aquellos que poseen edades comprendidas entre los 15 y los 40 años, los dichos que ellos consideran más conocidos se presentan a continuación: "Jalarse una torta", "agarrarse", "wila", "mamita", "mi amor", "borracho", "okey", "pongamos (digamos)", "nada que ver", "pulsear", "sia tonto", "nombres", "ahuevado", "pura vida", "vuelto", "ponerse vivo", "juepuña”, "plata" y "pegar gritos".

Estos 19 dichos son conocidos por el 100\% de la población y como es posible observar, los únicos que coinciden con respecto a la población adulta, son "vuelto" y "Sia tonto". Las razones pueden ser más de tipo idiosincráticas que de cualquier otro tipo. Palabras como vuelto para referirse al cambio han sido ampliamente utilizadas por muchas generaciones dentro de nuestra cultura y por ende es tal vez un término que llegó para quedarse, prueba de ello es la popularidad con la que goza tanto entre la población adulta como en la joven.

Es interesante observar como anglicismos como la palabra "okey" es muy popular entre la población joven pero no lo es tanto para la población adulta, lo mismo sucede con cariñativos del tipo "mamita" y "mi amor", de igual forma la frase "nada que ver" es más comúnmente escuchada entre la gente joven, inclusive en niños y niñas. Parece ser que efectivamente la edad tiene influencia en las palabras que la población conoce aun a pesar de que estamos hablando de una población con muchas características en común y que además son personas que constantemente están interactuando las unas con las otras en relaciones de tipo laboral y o comercial.

En lo que respecta a los dichos menos conocidos o menos populares dentro de la población adulta, es posible enlistar los siguientes ejemplos: "ponerse vivo", "mi amor", "juepuña", "pegar gritos", "jalarse una torta", "vacilar", "solo bueno", "no componer", "wila", "mi chiquita", "rendir" y "agarrarse".

Lo realmente interesante en este caso es el hecho de que dichos como "agarrarse", "wila”, “jalarse una torta”, "pegar gritos", “mi amor" y "ponerse vivo" que aparecen entre los menos conocidos por parte de la población adulta son parte de los dichos más conocidos para la población más joven. Particularmente "ponerse vivo" es conocido únicamente por un $57 \%$ de la población adulta pero es conocido en un $100 \%$ por la población joven.

En cuanto a la población más joven los dichos menos conocidos son los siguientes: "mano e' pulpo", "puñalados", "vestidura", "un día suave", "perro que bebe huevos", "ni quemándole el hocico", "di", "no componer", "a manos limpias", "menear", "lucharla", "rendir", "solo bueno", "quemar un lugar", "ver y desear", "andar a la patada" y "pa'ca".

Nuevamente aparece un contraste generacional entre la población mas joven y la que es más adulta. Dichos como "menear", "lucharla", "quemar un lugar", "Pa'ca", y "un día suave", son conocidos por el $100 \%$ de los adultos entrevistados pero son a su vez únicamente populares para menos del $84 \%$ de la población joven, de hecho un dicho como "un día suave" es popular para únicamente un $73 \%$ de la población joven pero el $100 \%$ de los adultos lo conoce.

En lo referente al uso de los dichos, para la población más adulta de los entrevistados, los dichos más utilizados son los que se presentan a continuación: "sia tonto", "toda esa cuestión", "menear", "nada que ver", "pulsear", "yay", "carajada", "tembladera", "lucharla", "pa'ca", "un día suave".

En este caso, dichos como "sia tonto" y "toda esa cuestión" es utilizado por un $100 \%$ de la población adulta del mercado central de Puntarenas. Y muchos de los dichos ahí presentes son a la vez parte de los dichos más conocidos para la población, es decir, existe una correspondencia directa en casos como "sia tonto", "toda esa cuestión", "menear", "Nada que ver", "carajada" y "lucharla".

En cuanto a la población más joven, los dichos más utilizados, según los resultados que arroja el instrumento aplicado son los siguientes: "tembladera", "pelar el ojo", "mamita", "yay", "ver y desear", "agarrarse", "sia tonto", "no 
hay que echar para atrás", "rendir", "pa’ca”, y “a manos limpias".

Los resultados en este apartado son muy particulares. Primero que nada, ninguno de los dichos es utilizado por un $100 \%$ de los entrevistados. De hecho, "tembladera" alcanza únicamente un $84 \%$ de personas que afirman hacer uso de él. El otro punto interesante es el hecho de que si se revisa la tabla que contiene los resultado de los dichos más conocidos y esta que contiene los dichos más utilizados, no hay una correspondencia directa salvo en los casos de "mamita" y "agarrarse" que se mencionan en los dos apartados. Este podría ser un fenómeno muy interesante de analizar.

En lo referente a los dichos menos utilizados, se puede ver que para la población adulta destacan los siguientes: "ponerse vivo", "mi amor", "pegar gritos", "no componer", "jalarse una torta", "juepuña", "vacilar", "wila", "di", "mi chiquita" y "solo bueno".

En este punto es muy interesante el poder observar como la correspondencia entre los dichos menos conocidos y los menos utilizados por la población adulta es casi que la misma, de hecho, dichos como "ponerse vivo" y "mi amor" poseen una correspondencia idéntica en los dos apartados. El único dicho que no coincide entre uno y otro es "di" que aparece entre los menos utilizados, pero no se vislumbra entre los menos conocidos.

Para la población más joven los dichos menos utilizados son: "mi amor", "vacilar" "veá", "andar a la patada", "pura vida", "pellejear", "jodida", "vestidura", "wila", "okey", "nombres", "juepuña", "pegar gritos", "chiles", "bretear", "lloradera" y "mano e' pulpo".

En lo que respecta a los dichos que son menos utilizados por la población más joven del mercado de Puntarenas nuevamente aparece una contradicción entre los dichos que clasificaron como los menos conocidos y los que ahora aparecen como los menos utilizados. Es interesante ver como este fenómeno únicamente se presenta en la población joven más no en la adulta. Al parecer los jóvenes conocen ciertos dichos, pero simplemente no hacen uso de estos. Esta población es un poco más inconstante que la adulta.

\subsection{Refranes conocidos y utilizados en el mercado central de Puntarenas}

Dentro de la totalidad de la población hay una serie de refranes bastante populares que son del conocimiento de todos los entrevistados dentro del mercado de Puntarenas. Sin embargo, al mismo tiempo existe una brecha entre los diez refranes más populares y los 3 últimos. Parece ser que no todos los entrevistados han escuchado refranes tales como "Hay que poner los puntos sobre las íes", "Está más limpio que calzón de monja" y "al lugar que fueres, haz lo que vieres". Algunos de los entrevistados afirmaron conocer otras versiones de esos dichos. Por ejemplo, en lo que respecta a "Hay que poner los puntos sobre las íes", algunos afirman utilizar "Hay que poner las cartas sobre la mesa" ó "Hay que poner los puntos sobre la mesa". En el caso de "Está más limpio que calzón de monja", otras sugerencias fueron "esta más limpio que calzón de manta", "Está más limpio que gabacha de salonero", "está más limpio que los huevos de aquaman", "Está más limpio que el culo de María del Milagro París" y "Está más limpio que puta en semana santa". En lo referente al refrán menos popular ("al lugar que fueres, haz lo que vieres") no se ofrece versión alguna, simplemente la mayoría de la población desconoce su existencia.

En un nivel más específico, dentro de la población femenina los refranes menos populares mantienen exactamente el mismo orden ya mencionado. En el caso de los hombres, ocurre exactamente el mismo fenómeno. Por otra parte, en lo referente a la popularidad de los refranes según el género, se mantiene la misma tendencia en ambos casos.

En lo referente al uso de los refranes, se puede afirmar que ninguno es utilizado por el $100 \%$ de la población entrevistada. Lo que si se nota, y que establece una diferencia clara con respecto los datos relacionados a la popularidad de los refranes es que hay un refrán "El que ríe de último, ríe mejor" que se destaca como el más utilizado por los entrevistados más no así se destaca entre los más conocidos por la población. En lo referente a las ú ltimas posiciones, la tendencia no varía mucho con respecto a lo 
antes mencionado en relación al conocimiento o popularidad que gozan estos refranes dentro de la población del mercado central Puntarenas el refrán "al lugar que fueres, haz lo que vieres" se mantiene claramente como ultima tendencia a razón del uso que se le da por parte de los entrevistados, pero en este caso la distancia que existe entre este refrán y el más utilizado es aún más grande que en la que destaca su popularidad.

De manera mas específica, dentro de la población femenina, coloca como menos utilizado al refrán "al lugar que fueres, haz lo que vieres", seguido por "está más limpio que calzón de monja", y en tercera posición entre los refranes menos usados destaca "a Dios rogando y con el mazo dando". En lo que respecta a los hombres, el refrán menos popular es "está más limpio que calzón de monja", seguido por "hay que poner los puntos sobre las íes", y como tercer refrán menos utilizado se menciona "al lugar que fueres, haz lo que vieres".

Si nos basamos en la variable generacional, es posible observar que para la población adulta de este estudio, la lista de refranes más conocidos es: "A mal tiempo buena cara", "A quien le cae el guante que se lo plante", "Indio comido, puesto al camino", "El que ríe de último ríe mejor", "Donde manda capitán, no manda marinero", "El que anda con lobos, aullar aprende", "A caballo regalado, no se le mira el colmillo", "Al mejor mono se le cae el zapote", "Dios tarda pero no olvida", "Ropa sucia se lava en casa", "Quien mucho abarca, poco aprieta", "A gato viejo, ratón tierno", "Está más limpio que calzón de monja", "al lugar que fueres, haz lo que vieres".

El $100 \%$ de la población entrevistada afirma conocer todos esos refranes. De hecho todos ellos han siempre sido muy frecuentes dentro del léxico costarricense y efectivamente la población del mercado de Puntarenas no iba a ser la excepción.

Para la población más joven, los refranes más conocidos o populares son: "A mal tiempo buena cara", "A palabras necias, oídos sordos", "A quien le cae el guante que se lo plante", "Indio comido, puesto al camino", "No todo lo que brilla es oro" y "El que ríe de último ríe mejor". Los únicos que resultan conocidos para el 100\% de la población son estos 6. Como dato curioso, los refranes "Al mal tiempo buena cara", "a quien le cae el guante que se lo plante", "indio comido, puesto al camino" y "el que ríe de último ríe mejor" son también conocidos por el $100 \%$ de la población de mayor edad.

En lo referente al uso que se le da a los refranes en el mercado de Puntarenas, para la población de mayor edad dentro de este estudio, los refranes más comúnmente utilizados son los siguientes: "Indio comido, puesto al camino", "A caballo regalado, no se le mira el colmillo", "Quien mucho abarca, poco aprieta", "Al lugar que fueres haz lo que vieres". El $100 \%$ de los entrevistados afirma hacer uso de estos refranes, todos ellos además son conocidos por la totalidad de la población adulta.

Para la población más joven, por otro lado, los refranes más utilizados son los que se muestran a continuación: "A mal tiempo buena cara", "Dios tarda pero no olvida", "No todo lo que brilla es oro", "A quien le cae el guante que se lo plante", "Donde manda capitán, no manda marinero", "Indio comido, puesto al camino", "Perro que ladra no muerde", "El que ríe de último ríe mejor".

Dentro de los refranes más populares aparecen todos los que se mencionan en la lista anterior como parte de los refranes más populares, los únicos que no son parte de la primera lista son: "perro que ladra no muerde" y "Donde manda capitán, no manda marinero". Cabe mencionar que ninguno de los refranes enlistados anteriormente es utilizado por un $100 \%$ de la población joven, es más "al mal tiempo buena cara", "Dios tarda pero no olvida" y "No todo lo que brilla es oro", son los más utilizados y únicamente son usados por el 57\% de la población entrevistada. Esto apunta a que la población joven, muy a pesar de conocer diferentes refranes, simplemente no hace uso de ellos. Una situación muy diferente se puede apreciar dentro de la población adulta en la cual el conocimiento y el uso de los refranes es mucho más común, de hecho dentro de esos grupos existen al menos 4 refranes que son conocidos y utilizados por la totalidad de la población entrevistada. 
En cuanto a los refranes menos utilizados por la población entrevistada, se puede decir que para los adultos, los refranes menos conocidos o menos populares son: "Árbol que crece torcido nunca su tronco endereza", "perro que ladra no muerde", "a Dios rogando y con el mazo dando", "a palabras necias, oídos sordos", "no todo lo que brilla es oro" y "hay que poner los puntos sobre la íes".

De la lista anteriormente presentada, el refrán "Árbol que nace torcido nunca su tronco endereza" es el menos conocido, únicamente $70 \%$ de los entrevistados afirma conocerlo. En el caso de "perro que ladra no muerde" sigue con un $77 \%$ de la población que afirma conocerlo y "A Dios rogando y con el mazo dando" cuenta con un $81 \%$, mientras que los otros 3 que mencionan son conocidos por un $96 \%$ de los entrevistados. Los restantes 14 refranes de la lista total son conocidos por un $100 \%$ de los entrevistados en edad adulta, esto nos lleva a decir que efectivamente las personas de más de 40 años de edad dentro del mercado de Puntarenas poseen un amplio conocimiento en materia de refranes.

La población más joven que participa del estudio afirma que los refranes que menos conocen o que les son menos populares son los que se detallan a continuación: "Al lugar que fueres haz lo que vieres", "Hay que poner los puntos sobre las íes", "Está más limpio que calzón de monja", "A gato viejo, ratón tierno", "Quien mucho abarca, poco aprieta".

Estos cinco refranes aparecen como los menos conocidos para los jóvenes, de hecho, el refrán "Al lugar que fueres haz lo que vieres" es conocido únicamente por un $31 \%$ de la población joven que se entrevistó. De manera muy interesante, este mismo refrán es conocido por el $100 \%$ de la población adulta. De hecho parece ser que los refranes que para los jóvenes son menos populares son los que la población adulta afirma conocer más. El único refrán que parece ser muy poco conocido dentro de la población en general es "hay que poner los puntos sobre las íes", al parecer la gente dentro del mercado de Puntarenas conocer una versión que dice algo como "Hay que poner los puntos sobre la mesa" o "hay que poner las cartas sobre la mesa".
Por otro lado, con respecto al uso de acuerdo con la población de mayor edad dentro de los participantes del estudio, los refranes menos utilizados son los siguientes: "Árbol que crece torcido nunca su tronco endereza", "A Dios rogando y con el mazo dando", "A palabras necias, oídos sordos", "El que ríe de último ríe mejor", "Perro que ladra no muerde", "Hay que poner los puntos sobre las íes".

En este caso la correspondencia con respecto a lo que los mismos adultos manifestaron eran los refranes menos conocidos es bastante grande. De hecho de los refranes menos conocidos "A palabras necias, oídos sordos" y "no todo lo que brilla es oro" son los únicos que no forman parte de los refranes menos utilizados por la población adulta. Algo muy llamativo en este caso es que muy a pesar de que la población adulta en general posee amplio conocimiento sobre dichos y refranes, en lo referente al uso de los mismos si hay diferencias más grandes. Por ejemplo, dichos como "Árbol que crece torcido nunca su tronco endereza" y "A Dios rogando y con el mazo dando" son únicamente utilizados por un $55 \%$ de los entrevistados a pesar de ser conocidos por más del $70 \%$ de la población.

Por otra parte, para la población más joven dentro del mercado de Puntarenas, los refranes menos utilizados son: "A Dios rogando y con el mazo dando", "Hay que poner los puntos sobre las íes", "Quien mucho abarca, poco aprieta", "Al lugar que fueres haz lo que vieres", "Árbol que crece torcido nunca su tronco endereza", "Ropa sucia se lava en casa" y "El que anda con lobos, aullar aprende".

En este caso, refranes tales como "quien mucho abarca, poco aprieta" y "Al lugar que fueres haz lo que vieres" aparecen dentro de los refranes que más utilizados por la población adulta. Ambos refranes son utilizados por 31 $\%$ de la población joven contario al $100 \%$ de la población adulta que afirma hacer uso de ellos.

\section{Conclusiones}

En relación a los dichos, existe un amplio conocimiento de estos por parte de la población, 
de hecho la totalidad de la misma manifiesta conocer palabras como "Ahuevado" y iNombres!, sin embargo, los mismos no son utilizados por la totalidad de la población. Lo cual indica que el conocimiento o popularidad de un dicho o frase no presupone su utilización.

En muchos casos, la popularidad de los dichos entre ambos géneros se mantiene, por ende se puede decir que la variable de género no afecta el conocimiento que tiene la población entrevistada de estos. Sin embargo, en relación a la edad, existen muchas palabas como "pa'ca", "menear", "carajada" y "horita" que les son familiares a la población más adulta más no lo son del todo para la población más joven. Efectivamente parece ser que los dichos más conocidos y utilizados en un grupo son lo opuesto en el otro. Por ejemplo, dichos como "menear", "lucharla", "quemar un lugar", "Pa'ca", y "un día suave", son conocidos por el $100 \%$ de los adultos entrevistados pero son a su vez únicamente populares para menos del $84 \%$ de la población joven, de hecho un dicho como "un día suave" es popular para únicamente un $73 \%$ de la población joven pero el $100 \%$ de los adultos lo conoce. Otro caso muy particular que se destaca en esta investigación es el hecho de que en el caso de los adultos existe una correspondencia entre los dichos que dicen conocer y los que dicen utilizar en tanto que para la población joven esto no se aplica ya que parece ser que estos tienen un conocimiento más amplio de los dichos que el uso que hacen de ellos.

En cuanto a los refranes, se concluye que ninguno de los que se le presenta a la población es utilizado por la totalidad de la población. Esto se aprecia más en el caso de la población más joven en la cual ninguno de los refranes es usado por la totalidad de los entrevistados, de hecho refranes como "al mal tiempo buena cara", "Dios tarda pero no olvida" y "No todo lo que brilla es oro", son los más utilizados y únicamente son usados por el $57 \%$ de la población entrevistada. Esto apunta a que la población joven, muy a pesar de conocer diferentes refranes, simplemente no hace uso de ellos. La población de mayor edad sí logra mayor coherencia entre conocimiento y uso de refranes, existen al menos 4 refranes que son conocidos y utilizados por la totalidad de la población adulta. Es un hecho, la población de mayor edad posee un mayor conocimiento y hace un mayor uso de los refranes que la población más joven, esto, lingüísticamente es preocupante debido a que se aprecia que varias de estas frases están cayendo en el desuso y de continuar con esta tendencia podrían desaparecer del léxico Puntarenense en poco tiempo.

\section{Referencias}

Guías Costa Rica. 2011. Refranero costarricense (refranes). Consultado el día lunes 23 de abril de 2012 en: http://www. guiascostarica.com/pueblo/refranes.html

Instituto de Cultura y Lengua Costarricense. 2005. Refranes. Dichos. Consultado el día lunes 23 de abril de 2012 en: http://iclc.ws/blog/index.php?/archives/4Refranes.html.

Agüero, Arturo. 1996. Diccionario de Costarriqueñismos. San José: Asamblea Legislativa.

Chang Vargas, Giselle. 2009. Costarriqueñismos en el léxico del boyeo. Káñina, Rev. Artes y Letras, Univ. Costa Rica. XXXIII Especial: 107-117.

Ramos, Elvira. 2000. Elementos Léxicos y Construcción de Identidad en el Español de Venezuela. FERMENTUM, 10(29): 421-432.

Jiménez Castro, Marjorie. 2012. Diccionario de costarriqueñismos. Índices de mortandad léxica en frases zoonímicas. Káñina, Rev. Artes y Letras, Univ. Costa Rica. XXXVI (Especial): 125-134.

Zuluaga Gómez, Francisco. 2004. Locuciones, dichos y refranes sobre el lenguaje: 
unidades fraseológicas fijas e interacción verbal. FORMA Y FUNCIÓN, 18: 250-282. (C) Departamento de Lingüística, Facultad de Ciencias Humanas, Universidad Nacional de Colombia, Bogotá, D.C.

Chang Vargas, Giselle. 2005.Léxico de la pesca artesanal Puntarenense en el golfo fe Nicoya. Una aproximación etnográficosemántica en Chomes, Costa de Pájaros, Isla Chira y Puntarenas centro. Káñina, Rev. Artes y Letras, Univ. Costa Rica. Vol. XXIX (Especial): pág. 77-88.

Kamenetskaia Kotseruba, Sofía. 2010. Del dicho al hecho...Sobre el conocimiento del refrán en la ciudad de México. Paremia, 19: 83-94.

Gielber Simonet, Alf A. 2012. A lo tico, costarriqueñismos $y$ otras vainas. Quinta edición, ediciones Jadine, San José, Costa Rica.

Real Academia de la Lengua Española. Disponible en http://www.rae.es/recursos/diccionarios/ drae. Consultado en diciembre del 2012.
Robles, Sara. 2002. El español, lengua del mestizaje y la interculturalidad. Lengua en la cultura y cultura en la lengua: la publicidad como herramienta didáctica en la clase de E/ LE. Disponible en http:// cvc.cervantes.es/ensenanza/biblioteca_ele/ asele/pdf/13/13_0720.pdf. Consultado 22 de enero del 2013.

Espinoza Patrón, Alejandro. 2012. La variable léxica, glosa de expresiones identitarias en el departamento del Atlántico, Colombia. RAZÓN Y PALABRA, Primera Revista Electrónica en América Latina Especializada en Comunicación. Disponible en http://www.razonypalabra. org.mx/N/N81/V81/01_Espinosa_V81.pdf. Accesado 22 de enero del 2013.

Catillo Fadic, Natalia. 2002. El préstamo léxico y su adaptación: un problema lingüístico y cultural. ONOMAZEIN, 7: 469496. Disponible en http://www.onomazein. net/7/prestamo.pdf.

Yule, George. 2010. The study of language. $4^{\text {th }}$ edition. New York. Cambridge University press.

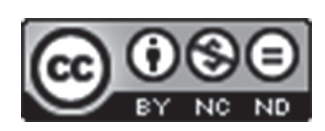

Este obra está bajo una licencia de Creative Commons Reconocimiento-NoComercial-SinObraDerivada 4.0 Internacional. 
